\title{
Online student support: a framework for embedding support interventions into the online learning cycle
}

\author{
O. $\operatorname{Rotar}^{*}$ (1)
}

\section{*Correspondence: \\ olga.y.rotar@gmail.com Present Address: Centre for Higher Education Research and Evaluation, Lancaster University, Bailrigg} Lancaster LA1 4YW, UK

\begin{abstract}
Support is one of the crucial elements of online students' success. Although many support strategies have been documented in the past, less is known at what stages of the learning cycle suggested interventions can be embedded into the online learning curriculum. This paper offers a systematic review of the 28 empirical studies on effective support strategies and interventions that are indexed by the SCOPUS database between 2010 and 2020. Following an Inclusive Student Services Process Model framework, identified strategies are allocated across different phases of student learning to indicate where and when they can be delivered to online students. The analysis suggests that the effectiveness of the support provision depends on the time when support is offered. Furthermore, it was found that two areas support delivery, namely support at transitions and measurement of support interventions, remain under-researched. Finally, the analysis showed two emerging trends in online students support: an increasing role of technology and social network sites to design support interventions and a shift to a more personalised yet holistic approach to student support.
\end{abstract}

Keywords: Student support, Support strategies, Embedded support, Online higher education

\section{Introduction}

Successful learning at a distance requires students to possess specific skills and attributes. As Brindley (2014) emphasised, "studying at a distance requires maturity, a high level of motivation, the capacity to multi-task, goal-directedness, and the ability to work independently and cooperatively" (p. 278). Furthermore, she stated that,

Distance learners are expected to plan their academic programs, set their study schedules, balance their studies with other responsibilities (work/family), communicate proficiently in writing, find and use learning resources well, and read and synthesise efficiently. Those distance learners studying in cohorts are expected to collaborate effectively with their peers in virtual groups, and those studying in selfpaced courses are often expected to create their own learning networks (Brindley, 2014, p. 278). 
However, mentioned above prerequisites may not be present in all students, and many online learners face challenges and barriers in their learning (Martin \& Bolliger, 2018; Stone, 2017; Woodley \& Simpson, 2014). It is widely recognised that student support is critical for overcoming barriers to learning and ensuring learner engagement, motivation and success in online higher education (see Rotar, 2020; Muljana \& Luo, 2019). Although many support strategies are available for review, there were no attempts to systematically analyse them in relation to different stages of student learning. As a result, there is a lack of understanding of where and when student support can be embedded into the online learning curriculum (Rumble, 2000). To address limitations of the past research, this study poses the following research question: What support strategies and interventions can be offered to online students at different phases of the learning cycle?

By bringing together research on reported support strategies and interventions, this paper aims to generate insights into the development of a framework for embedding support interventions into the online learning cycle. In doing so, this paper offers a unique contribution to the research on student support within the field of online education.

\section{Literature review}

A provision of student support is a necessary element of online student success (Rumble, 2000) that has been recognised in the past (Woodley \& Simpson, 2014) and continues to be relevant within the research on student's attrition, retention, and dropout (Rotar, 2020). Different support models offer valuable conceptual frameworks for thinking about the approach to online student support (see Floyd \& Casey-Powell, 2004; Ryan, 2004; Simpson, 2008). Ryan (2004) advocated a "centrality of student-student communication for retention and study success" (p. 131). He proposed a logical framework for maintaining support for online learners with a student as a centre of the model and argued that his framework "is best situated within the knowledge of the distance student's lifecycle, from initial interest in distance education as a possible avenue for study, to inquiry at a particular institution, through academic counselling, to study and eventual graduation" (p. 127).

Floyd and Casey-Powell (2004) offered an Inclusive Student Services Process Model (ISSPM) where they summarised characteristics of successful support service and distinguished five phases of the learning cycle where support can be provided. Another model developed by Simpson (2008) advocates the need for proactive rather than reactive support interventions. Simpson's Proactive Motivational Support model (Simpson, 2008) contains motivation and psychology elements and determines a proactive student outreach as an effective support intervention.

The models of online student support evolved since the invention of the Internet. The Internet facilitated the emergence of customised and automated services that can be delivered by computers rather than humans (Brindley, 2014; Dollingeret al., 2020; Walsh et al., 2020). It also enabled an opportunity to include social elements, e.g., online interactions and engagement, into support interventions. As Zawacki-Richter and Anderson (2014) emphasised, "the online world itself affords new tools for communication, knowledge and skill acquisition, and peer and group support that was not available to earlier generations of distance students" (p. 23). 
Within the discourse on the affordances of the Internet, Moore and Kearsley (2012) introduced a theory of transactional distance that placed a significant emphasis on the development of an understanding of the very concept of online learner support. A new approach presented online student support as an intervention that intends to decrease a transactional distance between learners, a tutor, and an educational institution and helps the learner develop autonomy.

Whilst offering multiple benefits for providing new forms of student support via advanced technological and pedagogical tools, there has been a criticism of the potentially oppressive nature of online learning environments (Öztok, 2019; Rice et al., 2020). Such criticism resulted in the turn to the humanistic view on online student support, which placed a greater emphasis on personalised learner support. Research on online students' experiences and perceptions also confirmed that embodied humanistic (as opposed to mechanistic) approaches for online learning support are critical for transformative learning experiences (Brown \& Wilson, 2016; Sewart, 1993; Stone, 2019; Thorpe, 2002).

The reviewed literature highlights the evolution of support strategies from depersonalised and additional services into the more targeted and tailored to diverse student bodies' needs, emphasises the increasing utilisation of the affordance of the Internet in offering support interventions. As Brindley (2014) states, "support systems for distance learners have become more proactive, more purposeful, and more effective in helping learners succeed in their studies". (p. 305). Furthermore, the literature suggests that the consideration of the stage where support is offered is essential for the support strategy to be effective (Floyd \& Casey-Powell, 2004; Ryan, 2004). However, little research has been done to systematically analyse specifically designed for online students support strategies or interventions in relation to the stages where they can be best implemented. By bringing together research on online student support strategies and interventions, this paper aims to generate insights into the development of the embedded support system that incorporates different phases of the learning cycle. In doing so, this paper offers a unique contribution to the research on student support within the field of online education.

\section{Analytical frame}

To analyse the identified support strategies and interventions, I employ an Inclusive Student Services Process Model (ISSPM) developed by Floyd and Casey-Powell (2004). The ISSPM is based loosely on Miller and Prince's (1976) student development process model, which was intended to "meet the needs of all students, to plan for change rather than react to it, and to engage the full academic community in this collaborative effort" (p. 21).

In the ISSPM, Floyd and Casey-Powell (2004) summarised characteristics of successful support services and distinguished five phases of the learning cycle where support can be provided namely the student intake phase, student intervention phase, student support phase, the student transition phase, and a measurement phase. The focus during each phase is summarised in Table 1.

The ISSPM framework is useful for the analysis as it identifies essential tasks for each stage of student learning and provides examples of support services that can be offered. 
Table 1 Five phases of the learning cycle in the ISSPM model

\begin{tabular}{ll}
\hline Phase of the learning cycle & Focus of support services \\
\hline Intake & Assessment of students' readiness for learning and negotiation of the goals \\
Intervention & Assistance and support to become independent and self-directed learners \\
Support & Encouragement and assistance in acquiring self-development strategies and skills \\
Transition & Career development and counselling services that assist students in their per- \\
& sonal and professional transitions \\
Measurement & Evaluation of the effectiveness of an educational program, including a provision \\
& of student support services, through feedback mechanisms
\end{tabular}

The five stages of this multidimensional model offer a systemic and targeted approach to student support, placing the needs of students upfront. Furthermore, it suggests that the successfully support service holds the potential to benefit both learners and an educational institution. Thus, the application of the model as an analytical frame provides a wide angle for the analysis of the existing online student support strategies and interventions and assists in addressing the research question.

\section{Methodology}

This paper offers a systematic review of the online student support strategies and interventions reported over the last ten years. Furthermore, it provides a thematic analysis of recommendations for student support offered in the empirical studies in relation to the five stages of the learning cycle where identified strategies fit the best.

To examine online students' support strategies and interventions, I considered studies published from 2010 to 2020 in peer-reviewed journals. To identify relevant studies, a set of inclusion and exclusion criteria has been set:

1. Due to the application of the ISSPM (Floyd \& Casey-Powell, 2004) as an analytical frame, only research focused on the conception of online student support within the scope of five stages of the learning cycle: (1) intake stage, (2) orientation stage, (3) support stage, (4) transition stage and (5) measurement stage has been included into the analysis.

2. Only empirical studies have been considered. Non-empirical and opinion papers were excluded.

3. Only research that reported a concrete support strategy or support intervention within the scope of five stages of the learning cycle had been included in the further analysis.

4. Only peer-reviewed papers published in the English language between 2010 and 2020 have been considered. The ten-year period has been set to examine the most up-to-date literature on online students' support.

\section{Identification of the relevant studies}

I adopted the identification process that involved three phases: searching, screening and analysis (Karabulut-Ilgu et al., 2018; Muljana \& Luo, 2019). 


\section{Searching}

Relevant studies were retrieved through a series of search efforts. Eligible research that meets the selection criteria were then identified. The search was carried out in two stages. First, an initial search was performed in the Scopus database. Keyword searches were conducted using the combinations of terms "support strateg*", "support intervention", "student support" AND “online education", “online higher education”, “online learning", "distance learning", "distance education". Keywords have been selected to reflect the scope of this research and the research question. As a result, I identified 180 peer reviewed articles from this phase of searching.

\section{Screening}

The screening process aimed to identify relevant studies by reading the abstract of the paper and by application of the selected criteria. During this process, articles that did not meet the inclusion criteria (e.g., non-empirical articles, opinion papers, not peerreviewed papers) were excluded from the further analysis. Additionally, duplicate reports of the same study were eliminated. The abstract screening yielded 38 peer-reviewed articles on the topic of interest for this paper, published between 2010 and 2020.

\section{Analysis}

The analysis process consisted of full-text reading. At this stage, several non-empirical studies and studies that deviate from the focus of this paper (e.g., articles that reported support interventions that do not fall into any phase of the learning cycle) have been identified and excluded from the analysis. The process of analysis resulted in a pool of 28 articles. All articles were arranged in tabular form. Five phases of the learning cycle have been analysed applying the ISSPM framework (Floyd \& Casey-Powell, 2004). During the analysis phase, I identified additional literature that did not meet inclusion criteria but was relevant for enhancing the analysis and discussion.

\section{Results}

In the following part of the paper, I discuss the results of the systematic literature review of the studies that reported online student support strategies and interventions. The summary of the identified relevant studies is presented in Table 1 . The Table contains the details of selected studies, including author (s), publication date, considered strategy, and its effectiveness.

\begin{tabular}{lll}
\hline References & Strategy & Reported effectiveness \\
\hline $1 \quad$ Walsh et al. (2020) & $\begin{array}{l}\text { Leveraging learning analytics } \\
\text { to provide highly responsive } \\
\text { student support }\end{array}$ & $\begin{array}{l}\text { The reported approach uses } \\
\text { personalised data-driven approach } \\
\text { that proved to increase student } \\
\text { retention, satisfaction, and facili- } \\
\text { tated a smooth transition to the HE } \\
\text { Kelly et al. (2020) }\end{array}$ \\
& $\begin{array}{l}\text { A holistic and coordinated } \\
\text { approach with three initiatives: } \\
\text { self-access resources and videos, } \\
\text { videoconference appointments } \\
\text { and peer-to-peer virtual guides } \\
\text { to online learning }\end{array}$ & $\begin{array}{l}\text { The authors emphasised flexibility } \\
\text { and personalisation of developed } \\
\text { andividual support options }\end{array}$ \\
& $\begin{array}{l}\text { peers, advisers and librarians for } \\
\text { technical and academic support }\end{array}$ \\
\hline
\end{tabular}




\begin{tabular}{lll}
\hline \multicolumn{1}{c}{ References } & Strategy \\
\hline $3 \quad$ Dollinger et al. (2020) & $\begin{array}{l}\text { Online service Studiosity with } \\
\text { an online live chat and a writing } \\
\text { submission functions }\end{array}$
\end{tabular}

Reported effectiveness

The vast majority of students reported that the service provided by the third provider assisted their learning, contributed to the higher grades, increased students' confidence and increased likelihood of retention. A significant proportion of students interacted with the service outside the traditional study hours
A comprehensive online orientation program. The modules Plan, Prepare, and Connect consisted of a suite of online resources, academic video presentations, step-by-step guides, quizzes and interactive, live sessions. Individual examples are interactive "Meet the experts" Zoom session session on how to navigate Discover La Trobe (a key module to support student transition), and "Getting Prepared for Study" quiz

Targeted student support for identification of students' needs

Wiki-site for the development of students' personal knowledge management (PKM) skills

An online information literacy module offered within the learning management system

Preparation skills for university online course

Feedback system in the form of multi-draft formative assessments. Diversification of feedback strategies
Multiple aspects of the orientation program proved to assist with focusing students' attention on organisation and time management skills prior to commencing their studies. Peer mentoring was incorporated into the orientation program to assist students in setting expectations and informing themselves about the demands and realities of online learning. It also assisted in developing important for online learning skills, such as how to plan and prepare for their studies and provided time management advice and techniques

The study showed that the provision of targeted support reduces attrition, escalated retention and success rate. Students classified financial support and academic support as critical for their success. Respondents over 35 years showed a greater need for technical support

Students perceived the helpfulness of using the wiki site to support PKM in online courses, but they less agreed with the helpfulness of using the group method to share tacit knowledge or "socialization" strategy

Students who participated in the online information literacy module had better student outcomes than those that did not participate in the module

Online resources, e.g., video recorded lectures, "talking heads" also personalised their experience. A supportive online environment was achieved by reducing anonymity of support, and by addressing students' personal needs in parallel with academic ones

The authors reported the impact of clear expectations and feedback on student performance. The frontloaded feedback approach (lesson on how to understand feedback before the feedback itself) helped students to read and understand the feedback better not only helped students learn but 


\begin{tabular}{lll}
\hline \multicolumn{1}{c}{ References } & Strategy \\
\hline $10 \quad$ Kumar and Johnson (2017) & Structured peer feedback \\
& strategy within online groups. \\
& Mentors provided scaffolds in \\
& the form of job-aids, step-by- \\
& step activities, and templates, \\
& discussed the research process \\
& and quality dissertations \\
& Peer support groups for doctoral \\
& students with the aim to connect \\
& students with common research/ \\
& krofessional interests during the \\
& dissertation writing phase
\end{tabular}

12 Sisselman-Borgia and Torino (2017)

13 Walters-Archie (2018)

14 Glazier (2016)

15 Kear et al. (2016)

16 Brown and Wilson (2016)

17 Kuo and Belland (2016)

18 Nichols (2010)

\section{Reported effectiveness}

Feedback offered in a form of structured group mentoring helped to reduce challenges of non-verbal communication in the online environment and provided mentees with academic, personal and other forms of support

All study participants reported that support initiative has been imperative for their persistence and completion of the doctoral degree. Nominated mentors provided structure for the students in the form of deadlines, clear timelines for submission and tutor response, regular individual and group meetings, timely and meaningful feedback. The mentors also facilitated the management of peer feedback within and across different groups

Authentic learning experiences

Authentic tasks and designed activities smooth the transition from educational to the professional field

Four phases of a holistic orientation programme: (1) introduction and navigation; (2) introduction to the programme structure and requirements; (3) introduction with the focus on the active engagement of students into discussion,quizzes, etc.; and (4) interaction with course facilitators within individual courses

Rapport-building teaching strategies

Online tester experience

The majority of students (94\%) found the first three phases of the online orientation beneficial

High-rapport relationship with the instructor suggested to influence student success and retention

The strategy allowed students to evaluate skills, readiness for studying online and clarify expectations before the enrolment

Two strategies (Caring Groups up to five students, and Caring Connections online sites) that promote culture of caring for self and for others

Two unique strategies reported to be effective means to foster social presence and engagement and contributed to the development of a dynamic online community. The Caring Connections site provided safe space for sharing motivational messages, self-care tips, music, and photographs, etc. between the faculty and students

Pre-class training on the Internetbased technology

Readiness for distance study survey, orientation course, general messages of support, and personal contact
Offered strategy facilitated students' online interaction and overall learning experience and progress

The results of the study showed that support interventions positively influence student retention, particularly with first-time online learners and level 5 students. The study showed that students are sensitive to the lack of support but tend to not appreciate it when support is in place 


\begin{tabular}{|c|c|c|c|}
\hline & References & Strategy & Reported effectiveness \\
\hline 19 & Whitelock et al. (2015) & $\begin{array}{l}\text { Catch up and review weeks } \\
\text { embedded into the course } \\
\text { schedule }\end{array}$ & $\begin{array}{l}\text { Strategies for recognition and } \\
\text { management of the additional } \\
\text { workload proved to increase reten- } \\
\text { tion for students with multiple } \\
\text { responsibilities }\end{array}$ \\
\hline 20 & Gibau (2015) & Intentional peer mentoring & $\begin{array}{l}\text { Intentional connection of students } \\
\text { with mentors proved to support } \\
\text { students in their transition to the } \\
\text { university }\end{array}$ \\
\hline 21 & Gaytan (2015) & $\begin{array}{l}\text { Comprehensive feedback and } \\
\text { instruction }\end{array}$ & $\begin{array}{l}\text { A more comprehensive feedback } \\
\text { and instruction on how to engage } \\
\text { in corrective behaviours was found } \\
\text { to improve retention }\end{array}$ \\
\hline 22 & Robb and Sutton (2014) & Motivational emails & $\begin{array}{l}\text { Motivational emails significantly } \\
\text { enhanced final course grades, } \\
\text { course interest survey scores, } \\
\text { facilitated students'learning and } \\
\text { decreased discomfort }\end{array}$ \\
\hline 23 & McLoughlin and Alam (2014) & $\begin{array}{l}\text { Students were taught how to } \\
\text { effectively use social media and } \\
\text { Web 2.0. tools, including blogs, } \\
\text { podcasts, Twitter and wiki }\end{array}$ & $\begin{array}{l}\text { Students reported benefits of } \\
\text { collaboration, sharing and peer } \\
\text { networking as major advantages } \\
\text { of the use of social media. Twitter } \\
\text { was most popular tool to create a } \\
\text { culture of engagement and peer } \\
\text { interaction }\end{array}$ \\
\hline 24 & Britto and Rush (2013) & $\begin{array}{l}\text { Comprehensive student support } \\
\text { system }\end{array}$ & $\begin{array}{l}\text { An introduction of the number } \\
\text { of support services showed } \\
\text { an impact in terms of comfort } \\
\text { level with taking online courses, } \\
\text { increased technical support, } \\
\text { improved communication } \\
\text { between students and advisers, } \\
\text { increased access for fully online } \\
\text { students to academic advisers }\end{array}$ \\
\hline 25 & Nicholas et al. (2012) & $\begin{array}{l}\text { Evaluation of pre- and post-inter- } \\
\text { ventions of social support }\end{array}$ & $\begin{array}{l}\text { Evaluation of the offered social } \\
\text { support showed an increase in } \\
\text { quality of online students' relation- } \\
\text { ships with other people, decrease } \\
\text { in the feeling of isolation, and } \\
\text { enhanced knowledge gain }\end{array}$ \\
\hline 26 & Smailes and Gannon-Leary (2011 & Educational scaffolding & $\begin{array}{l}\text { A provision of scaffolding positively } \\
\text { influenced students' motivation }\end{array}$ \\
\hline 27 & Purnell et al. (2010) & $\begin{array}{l}\text { Automatic feedback that incor- } \\
\text { porates rankings with suggested } \\
\text { strategies that would assist the } \\
\text { student in commencing their } \\
\text { university }\end{array}$ & $\begin{array}{l}\text { The support intervention allowed } \\
\text { students to develop more realistic } \\
\text { expectations about managing } \\
\text { studies, maintaining motivation. } \\
\text { This strategy is targeted at risk } \\
\text { students at risk and proved to } \\
\text { minimise time between identifica- } \\
\text { tion of vulnerable students and } \\
\text { a proactive outreach of those } \\
\text { students }\end{array}$ \\
\hline 28 & Boyle et al. (2010) & Peer-mentoring support & $\begin{array}{l}\text { Students reported an increased } \\
\text { feeling of belonging, motivation, } \\
\text { improved study skills, communi- } \\
\text { cation with the tutor, as well as } \\
\text { were able to discuss workload and } \\
\text { personal problems }\end{array}$ \\
\hline
\end{tabular}

Following the ISSPM framework, the identified support strategies, recommendations and interventions are allocated across the five phases of the educational life cycle to indicate the areas where they can be embedded into the online learning curriculum. 


\section{Student Intake Phase}

Advising prior to enrolment

Past research advocates the provision of advising services on various aspects of learning prior to the enrolment (Cain \& Lockee, 2002; Clay et al., 2008). It was found that the lack of comprehensive information about the chosen online programme was a main cause of misconceptions about requirements and a difficulty of the course (Clay et al., 2008). The review of the considered studies also supported the importance of the preenrolment advising. Gaytan (2015) believes that academic advisors must articulate study agreements regarding the credit transfer more clearly and provide advising strategies to ensure that students receive credit for previous coursework. Another example is a mandatory pre-enrolment initiative is an online readiness survey (Nichols, 2010). The author proposed that such a survey provide students with essential information needed for the decision-making process and decrease the mismatch in students' expectations.

\section{Orientation}

Orientation programmes are proven to support student transition to the higher education (HE) and ensure the "scaffolded entry" (Stone, 2019, p. 5) to the online learning environment (Horvath et al., 2019; Nichols, 2010; Walters-Archie, 2018). This support strategy implies a "greater emphasis at the front end" (Stone, 2019, p. 5) and an establishment of an early connection with students (Gaytan, 2015). Through the orientation programme, students can also access "online tester experiences" (Kear et al., 2016, p. 141) that allow them to evaluate their online learning skills and readiness to study in the online learning environment. As emphasised in the E-excellence framework, "students should be informed prior to registration about the skills they will need to develop, and the study skills support available to them" (Kear et al., 2016, p. 141).

Orientation programmes also prepare students for their learning online after the enrolment. One example is a holistic pre-course orientation programme (see WaltersArchie, 2018) that consisted of four phases: an introduction to the online learning environment with the focus on navigation skills, an introduction to the structure and requirements of the programme, an introduction to the learning environment with the focus on practical activities (e.g. group discussions, quizzes), and an introduction to course facilitators. Walters-Archie (2018) reported that $94 \%$ of students found the orientation programme beneficial. Another example is orientation programme designed by Horvath et al. (2019) that include three modules, namely plan, prepare, and connect. Each module provides students with learning resources, video presentations, study guides, "Meet the experts" interactive Zoom seminars and "Getting Prepared for Study" quizzes that aim to clarify student expectations, present available support services and enhance students' engagement.

\section{Intervention phase}

Identification of students at- risk and early interventions

Netanda et al. (2019) found that novice online learners are also at a greater risk to face challenges when adjusting to the online learning environment than more experienced learners (p. 405). According to Purnell et al. (2010) "early intervention with weaker achieving student" enhance student retention (p. 78). 
Identification of students at risk has been also emphasized in the past research (Gibbs et al., 2006; McKavanagh \& Purnell, 2007). McKavanagh and Purnell (2007) pointed at distinctive features of those students such as lack of motivation, unrealistic time management expectations, and hesitation to reach for help (p. 79). In the United Kingdom Open University (UK OU) vulnerable or at-risk students have been identified based on the analysis institutional data (e.g. students' sex, age, educational and professional experience) (Gibbs et al., 2006). A proposed support strategy involved contacting those students who have been identified as needing advice or support in order to offer them an appropriate help (Gibbs et al., 2006). Similarly, Simpson (2008) argued that in the situation of scarce recourses the most effective way to improve student retention is to focus on those students who require support and are most likely benefit from it. What makes a difference for at risk student retentions is the time between the student identification and a time of support intervention (Gibbs et al., 2006; Purnell et al., 2010).

\section{Proactive support and student outreach}

Empirical studies confirm the importance of proactive rather than reactive support for online distance learners. Robb and Sutton (2014) showed that motivational emails initiated by the educational institution significantly enhanced final course grade and course interest survey scores. Students reported that such emails encouraged them to put more effort into learning and eliminated discomfort in communication with their tutors. Core strategies for proactive tutor support in the UK OU included consideration of the students' workload and pacing students' learning against milestones, monitoring students' learning outcomes in order to identify those who are at risk of falling behind and dropping out and getting in touch with students prior to the submission of the first assignment in order to identify those who struggle academically (Whitelock et al., 2015). Proactively contact students using learning analytics have been also advocated by Walsh et al. (2020).

Past research also emphasised the importance of prolonged proactive interventions at the early stage of the learning cycle (Anderson, 2003). Similarly, Simpson (2003) emphasised a positive impact of the motivational calls and postcards on UK OU students' retention, speculating that motivational emails can have the same effect. Another example of proactive institutional support is an introduction of the possibility to re-submit an unsatisfactory assessment to individual students (Pinchbeck \& Heaney, 2017). It is notable that online tutors play an invaluable part in the provision of the proactive support. According to Rendon (1994), a validation of the tutor in the form of encouragement or an interest in the students' activities positively impacted students' learning. Simpson (2004) found that online distance learners who have been approached by a tutor via phone call with an encouraging conversation had higher retention at the end of the programme than the students who did not received this support.

\section{Addressing external factors}

Online students require support not only with their learning, but with balancing external factors and commitments (Sorensen \& Donovan, 2017; Stone, 2019; Whitelock et al., 2015). Whitelock et al. (2015) reported that the importance of the workload for online learners who have pressures with work and family responsibilities should be recognised 
and taken into consideration. Emerged from the overlap or clash of assignments with particularly busy periods of online students' life may result in the heavy overload and a student may fall behind. Thus, it should not be assumed that students are always on track of their study schedules. Instead, an introduction of catch up or review weeks can enhance students' motivation and contribute to their learning progress (Whitelock et al., 2015).

\section{Support phase}

\section{Mentoring and peer support}

Mentoring and peer support proved to improve students' adaptation to online learning environment (Kumar \& Coe, 2017), contribute to the development of communication skills, and result in the better academic performance (Ashwin, 2003) and a higher persistence (Congos \& Stout, 2003; McLean, 2004; Muldoon, 2008). Brindley (2014) argues that for educational institutions that have a constant enrolment in self passed learning an establishment of strong peer support networks in crucial for student success. Peer mentoring was the main mechanism in the designed by Horvath et al. (2019) orientation programme within which mentors helped new students to develop realistic expectations about their online learning, clarified the programme requirements, and overall served as learning models. Kumar and Coe (2017) too explained that through mentoring, new students can receive not only academic but also "socio-emotional support" ( $\mathrm{p}$. 15) since mentors play a mediating role for the knowledge and experience development. The participants of their study referred to the peer support as a paramount element for the development of community and persistence during the dissertation writing process.

Boyle et al. (2010) found that mentoring has a clear impact on student retention, offering a cost-efficient support strategy for the educational institution which is often underused in distance education. They proposed a "study dating" initiative designed to match students according to their characteristics, interests and other provided information (Boyle et al., 2010, p. 129). Such use of technology and social network sites is a new turn in establishing student support networks. Indeed, Internet can offer additional affordances for online peer support and mentoring (Dollinger et al., 2020; Hsiao \& Huang, 2019; Marineo \& Shi, 2019).

The relative simplicity of peer mentoring, a cost-effective strategy considered earlier, as a support strategy embedded into the learning curriculum is also neglected (Boyle et al., 2010). Although it involves an establishment of initial connections between students and assistance in developing a peer network from the side of educational institution, this strategy takes less effort from academic and administrative staff than any other intervention. As, Brindley (2014) pointed out, "as institutions grapple with how to continue to provide quality support to greater numbers of students, it is likely that peer support will become much more important" (p. 297).

\section{Care}

More attention has been paid to the indirect student support and caring. Robb and Sutton (2014) found that the student perception of a "caring instructor" (p. 6) or caring professor (Tippens, 2012) added a personal touch to the online class. Brown and Wilson (2016) proposed two initiatives, namely online caring groups and Caring connection 
website to facilitate students' habits to care for themselves and care for others in an online learning environment. Prior research also recognised the value of indirect support. Jones (2010) argued that academic caring is an important factor for online students' success. Similarly, Chen and Jang (2010) explain that students need to be surrounded by the atmosphere that allows a free expression of "feelings, thoughts, and concerns" (Chen \& Jang, 2010, p. 750), whereas the traditional form of depersonalised support can create barriers for expressing students concerns. Overall, an emphasis on care can facilitate genuine student connection with the educational institution and foster the development of the community of learners.

\section{A provision of structure}

Kumar and Johnson (2017) found that, from mentors' perspective, the structure and scaffolding in online learning environment are the necessary strategies for students' progress and elimination of the feeling of isolation. They found that organised group meetings and a provision of the peer feedback in a structured way assist students in being on top of their learning (p. 68). Smailes and Gannon-Leary (2011) also identified that a provision of scaffolding positively influenced students' motivation. Educational scaffolding items mentioned by the students in their study are the well-organized structure of the courses, weekly email prompts and active learning tasks (Smailes \& Gannon-Leary, 2011).

\section{Fostering a strong sense of community}

A community of learners is a "powerful motivator and a powerful mechanism" for supporting online students and their learning experience (Collins et al., 1987, in Boling et al., 2012, p. 121). Hew (2015) argued that online learning experience can be enhanced by the reinforcement of the "social nature of learning" through the community where learners can socialise and support each other's learning (p. 2).

Kumar and Coe (2017) supported a cohort model of learning that allows students to form meaningful interpersonal connections and be better supported in their learning challenges. In the past, "fostering sense of belonging" (p. 59) has been emphasised by Floyd and Casey-Powell (2004). Boyle et al. (2010) argued that feeling of belonging can be increased with the implementation of the peer support networks. Yet, individual institutions are recommended to identify communicative activities that work best for encouraging a greater sense of community among their students.

\section{Interactions}

Past research showed that well designed interactions improve students' satisfaction, retention (Rienties \& Toetenel, 2016) and learning outcomes (Kuo \& Belland, 2016; Richardson et al., 2017). Boling et al. (2012) argue that online students' connection with their tutors remains the most significant success factor. Among strategies to facilitate learner - content interactions Kuo and Belland (2016) suggested the use of technology enhanced tools (e.g., audio and video materials, multimedia, software that facilitates students' learning) and a structured and easy to access online learning content. Interactions with the tutor can be enhanced by the provision of the encouragement and personalized guidance whereas the effectiveness of student communication can be facilitated through 
the guidance for interactions and collaborative work, with explanation of requirements, expectations, and online etiquette (Kuo \& Belland, 2016).

\section{Development of meaningful relationships}

In online student support literature, there is a noticeable emphasis on the development of meaningful relationships. Scholars found that a teacher engagement and connection with online students has a positive effect on retention numbers (Glazier, 2016; Stone \& O'Shea, 2019). Glazier (2016) identified that high-rapport relationship with the instructor is a key factor in student success and retention. To facilitate meaningful relationships, Glazier (2016) suggested implementing rapport-building teaching strategies, such as video updates, personal e-mails, and personalized electronic comments on assignments into online course.

Past research also indicate that the absence of the personal contact may result in the development of the feeling of loneliness (Sorensen \& Donovan, 2017) and create communicative barriers especially for the less proactive learners (Brown et al., 2020; Paechter et al., 2010). To support the development of meaningful relationships, the teacher is expected to take onboard additional responsibilities (Russo-Gleicher, 2013).

\section{Support with the development of necessary skills}

Support with the development of skills necessary for online study may enhance students' learning experience. Kuo and Belland (2016) found that pre-class training on the Internet-based technology facilitated students' online interaction and overall learning experience and progress. In the study conducted by McLoughlin and Alam (2014), students were assisted in developing skills to work with social media and reported benefits of collaboration and peer networking of such support. Hsiao and Huang (2019) too suggested the use of wiki site as a strategy to support the development of the personal knowledge skills. Students found this support useful for a better personal knowledge management but not so for the purposes of socialisation. The concrete strategies for the development of student skills that the authors proposed are a provision of training, guidance, and examples of peer feedback and a peer reviewing process that enhances the development of the personal knowledge skills. In other works, despite the potential for enhancing students' online learning experience the use of the Web.2.0. tools require guidance in how they are used by students and an ongoing evaluation of the effectiveness of their use.

Among interventions that support the development of online study skills reported in the past are time management and study management training for students with multiple priorities. Grant et al. (2011) designed an online study skills workshop aimed to develop students' self-directedness and online learning skills. McLoughlin and Alam (2014) advocated scaffolded teaching as a way to increase collaborative learning interactions and to develop social media skills. In their study, they used Twitter as a tool for group interactions and found that twitter facilitated the development of a unique culture of peer communication and engagement.

\section{Feedback}

For a diverse online student population, there is a need to re-think a meaningless and depersonalised provision of feedback. As Whitelock (2010) emphasised, timely and 
meaningful feedback influence online student progress as it is perceived as an "advice for action" (p. 323). Gaytan (2015) found that comprehensive feedback positively influences online students' academic performance, resulting in an increase of student knowledge and decrease of the feeling of frustration. Uribe and Vaughan (2017) proposed a feedback cycle, suggesting two phases of potential frustration and difficulties: an encountering of the formative assessment feedback and a situation when a student does not seek a feedback clarification. The authors found that in these phases students may experience misunderstanding and confusion. Thus, as Whitelock et al. (2015) argued, affective and cognitive domains of the tutor feedback should be balanced in different ways for different learners, providing them with an adequate combination of "socio-emotive and cognitive support" (p. 171).

\section{Personal advising and counselling}

Although in the reviewed studies personal advising and counselling has not been differentiated as distinctive strategies, they were advocated as a part of the wholistic approach to supporting online students (Kelly et al., 2020; Zuhairi et al., 2019; Britto \& Rush, 2013).

Research conducted in the past emphasises that the availability of advising services has direct impact on online students' satisfaction and course retention (Cain \& Lockee, 2002). Although such support is easily accessible for campus-based students, there is need for its provision for distance learners using multiple technological means, such as phone calls, emails, online conference tools. Furthermore, sufficient information about the personal support and counselling should be visible and available through the educational institution.

\section{Transition phase}

In the selected for analysis studies, there was no reference on concrete strategies or interventions at student transition points, apart from suggestions offered by Gibbs et al. (2006) and Gibau, (2015). Yet, past research emphasises that those timely interventions at transition points, between different parts of the study and during the induction period, make a positive difference in students learning progress (Baxter, 2012). Following types of transitions have been identified in the past: transition to higher education, transition between different stages of learning, and transition to the labour market.

\section{Transition to the higher education}

Although the literature on the strategies for supporting students at transition points is scarce, past research focused on the transition to higher education, and especially the literature on socialisation, suggests that novice students benefit from guided transition (Gibau, 2015; Ward \& Commander, 2011). Gibau (2015) explains that student transition often involves both social and physical adjustment (p. 6), which is in line with the models on students' retention and progress (Tinto, 1975; Rovai, 2003). Pedagogical models presume that if a student cannot make a social and academic adaptation, then the result may be dropping out from the course of study.

To prepare students for the initial transition to the HE, such an early outreach and "intentional peer mentoring"- also discussed in other phases- have been suggested 
(Gibau, 2015, p. 10) as strategies to support new students in their adjustment and transition to the higher education. Such activities contribute to the development of the kinship and can be arranged through matching different cohorts of students (Gibau, 2015).

\section{Transitions between different stages of learning}

The UK OU advocates focused support interventions in the periods of transition from one course to another to support students' decision-making process (Gibbs et al., 2006). For some students, support in transition is a motivating factor, particularly if interventions from both tutors and support staff can address the lack of confidence- a common feeling reported by students in a new situation or environment. Baxter (2012) explained that if students are not supported at these ambiguous stages, they may experience exclusion and fail to progress.

\section{Transition to the labour market}

Another form of transition is the transitions from the university to the labour market (Dahlgren et al., 2006; Merrill, 2020). In the study conducted by Sisselman-Borgia and Torino (2017), students reported that "it was difficult to make a transition into a new field of work without ever having an experience in the new field" (p.). Learning experiences that aim to provide students with authentic experience in the field and evaluate their fitness (but also being flexible enough to fit into their current schedules) are among previously employed support strategies (see Sisselman-Borgia \& Torino, 2017).

\section{Measurement phase Use of data analytics}

Learning analytics offered the potential to identify at-risk students based on predictor variables (Simpson, 2004). Moreover, institutional data allows matching the most appropriate strategies with students who may benefit from such support (Gibbs et al., 2006; Walsh et al., 2020). In the past, there were attempts to measure the effectiveness of student support strategies and interventions. For instance, Simpson (2004) proposed a "maximum possible increase in retention" indicator to measure the effectiveness of support strategies (p. 82). Using student data to conduct predictive models, educational institutions can develop targeted interventions and help learners make more informed decisions about available support services (Brindley, 2014).

\section{Cost-benefit analysis}

Although there was no data on the analysis of costs involved in the design of support interventions in the revised studies, prior research showed that employing the cost analysis can justify the concreate support strategy or intervention. In the UK OU, Gibbs et al. (2006) predicted a profit of $\$ 2,087,302$ a year by implementing a new proactive support system for 35.000 online students that cost $\$ 1,085,000$ per year (p. 371). Such evaluation allows implementing support strategy that is "backed by cost-effectiveness data based on evaluations of controlled experiments and driven by management information systems" (Gibbs et al., 2006, p. 259). Furthermore, the cost-benefit may assist educational institutions in designing personalised, yet cost-effective support interventions based on the analysis of institutional data to identify vulnerable and at-risk students. However, the 
analysis of the research on support strategies and interventions showed that there are no embedded mechanisms to evaluate student support interventions in terms of their economic costs and benefits.

\section{Surveys and interviews}

Surveys of satisfaction with support services are most often used to measure quality and identify any unmet needs (Brindley, 2014). Nicholas et al. (2012) conducted preand post-intervention interviews with two groups of students, those who received support and those who did not. Qualitative interviews with intervention group participants proved to be helpful in identifying the beneficial impact of support. Specifically, the researchers were able to collect data on students' decreased isolation, gain in knowledge, and normalisation of experience (Nicholas et al., 2012).

\section{Self-evaluation tools}

Higher educational institutions can use a variety of tools to assess the support services they offer. One assessment tool reported in the past is the Online Student Services Self-Assessment Tool, which helps educators review links to the support services and evaluate which areas of support are not addressed (Floyd \& Casey-Powell, 2004, p. 56). Among the considered studies, Boyle et al. (2010) also employed self-reports from online students to measure the effectiveness of the implemented peer support strategy. The data showed that mentored students had a higher persistence rate compare to the unsupported students. Analysis of such data helped to plan the further implementation of the peer-support strategy in the institution.

\section{Discussion}

The analysis of support strategies, initiative and interventions using the MIPS framework aimed to answer the research question What support strategies and interventions can be offered to online students at different phases of the learning cycle? Using Floyd and Casey-Powell (2004)' IMSS framework, I allocated identified support strategies for online students across different phases of the learning cycle. Figure 1 shows that various forms of support can be offered to students during the different stages of their learning.

The results of this study support prior research on the positive effect of initial student support during the student intake phase (see studies on orientation programmes House \& Kuchynka, 1997; Williford et al., 2001; Wilson, 2008).

At the student intervention phase, the analysis results appear to be in line with studies that advocate early and proactive interventions. Specifically, the findings support research on early measurement for identifying students' prior knowledge and behavioural characteristics that provide a clue for deciding on proactive intervention (Muljana \& Luo, 2019; Nistor \& Neubauer, 2010). The approaches to student outreach tend to utilise technologies and data analytics rather than the old form of proactive support such as telephone calls. Specifically, the use of learning analytics to identify at-risk students offers unlimited opportunities for targeted interventions (Simpson, 2004). This line of research holds the promise that predictor variables become more accurate in targeting students and the learner analytics approach more sophisticated. 


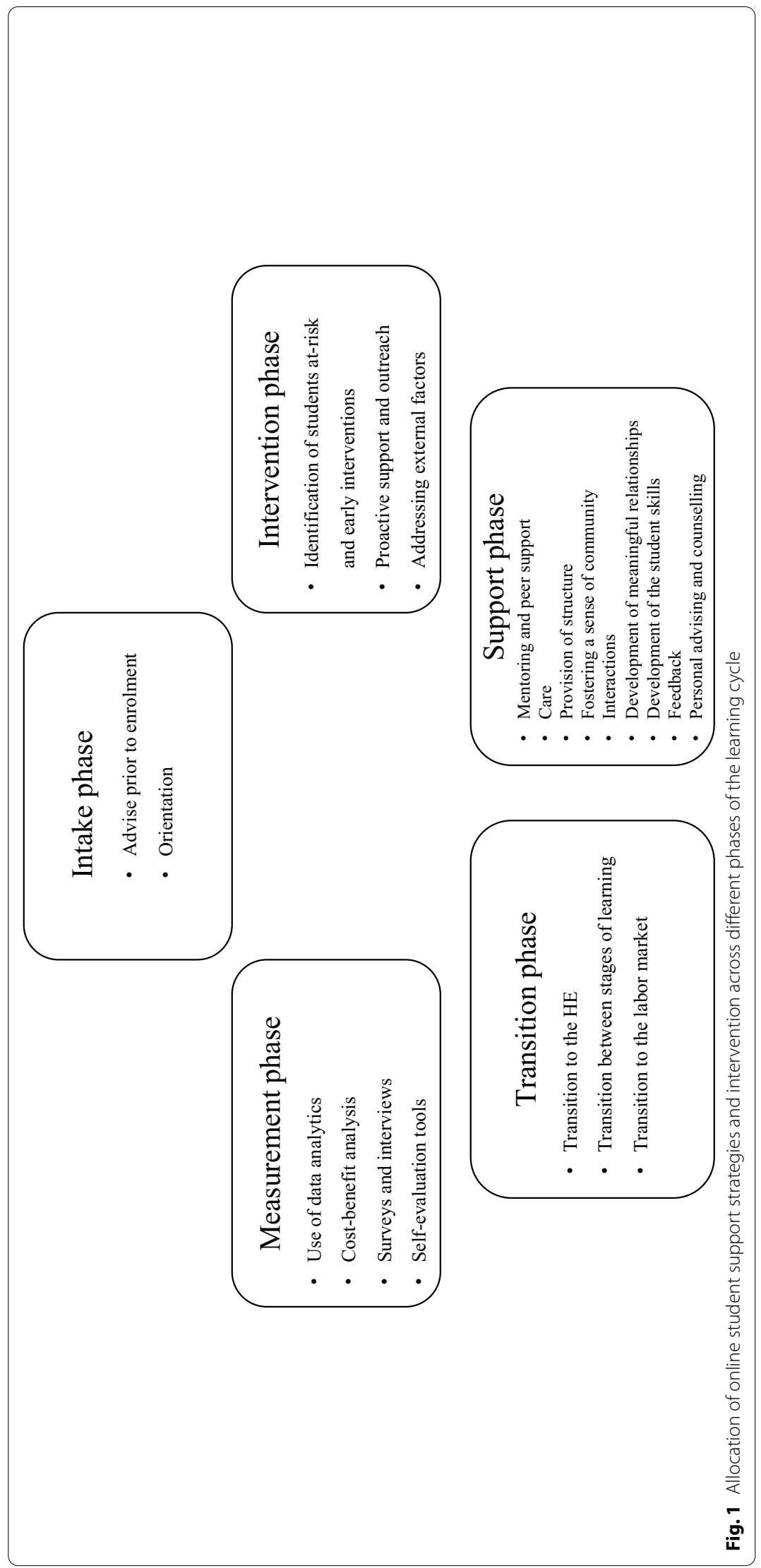


In regard to the student support phase, there are multiple ways in which support can be offered (Tait, 2004). This study confirmed the importance of advising and counselling, the development of the sense of community and support with academic skills- essential elements of support emphasised by Floyd and Casey-Powell (2004). The analysis also found that there is a recognition of the positive impact of peer mentoring and support for online student progress and retention. Moreover, this strategy is suggested to be relatively cost-effective. However, in an online learning environment, peer support and mentoring remain under-researched domains, and there is "little evidence of the existence of UK programmes of peer mentoring in virtual formats" (Smailes \& GannonLeary, 2011). Boyle et al. (2010) point out that "the key success factors consistently identified include appropriate mentor training and the inclusion of peer mentoring as part of the formal curriculum. (p.120). Thus, it is crucial to bear in mind that such conventional forms of student support may still have much to offer in enhancing student engagement and retention (Boyle et al., 2010).

The identified support interventions are in line with research that differentiates supports into academic, technological, and personal (Anderson, 2008; LaPadula, 2003). The study also recognises the importance to maintain a sense of belongingness to the community- key component that can combat student attrition and drop out (Lee \& Choi, 2011).

Systematic literature review revealed that two phases of the learning cycle- transition and measurement- are not well supported by the existing research on online student support strategies and interventions. However, this does not minimise their importance but rather reveals the lack of research in those areas. The transition phase showed the aspect of students' transitions, such as a transition to the HE, transitions between different parts of study and during the induction period, and any other forms of transition that require student adjustment to the new environment or routine. This is in line with scholars who emphasised the multifaceted nature of the process of transition (Hussey \& Smith, 2010; Maunder et al., 2013), which may involve not only educational adjustment but also personal adaptation and adjustment of the lifestyle. Past research suggests that there are different types of transition to which students require to adapt (Maunder et al., 2013). Maunder et al. (2013) emphasise that transitions not always associated with educational adaptation but may involve personal, lifestyle and identity adjustments (Cocquyt et al., 2017). Yet, most of the research on students' transitions have been predominantly focused on student transitions during the first year (Reay, 2003; Tett, 2000). Educators are invited to recognise the multifaceted nature of online students' transitions that can occur at different stages of their learning.

In regard to the measurement phase, the main finding of this study is that although attrition studies often conclude with recommendations for specific kinds of support interventions, relatively little evaluative research has been done to find out about their impact. Although, according to Rumble (2000), distance educational institutions are "more driven by concern for planning customer care and support than the traditional universities" (p. 219), mechanisms for measuring the suggested interventions are less developed. Tait (1995) emphasises that the rationale for online student support remains relatively weak and, therefore, continue to be "subject to wild fluctuations in terms of financial support" (Tait, 1995, in Rumble, 2000, p. 216). Gibbs et al. (2006) agree that 
in the situation of scarce resources, evaluations of cost-effective cases should be done to gather evidence on the impact, effectiveness, and value of the support interventions. The issue that the authors emphasise is that the recommendations have been developed predominantly within a controlled environment rather than tested in real learning situations. Moreover, they argue, there is no comprehensive system that evaluates the effectiveness of the developed interventions (Gibbs et al., 2006, p. 375). Therefore, more effective use of institutional data and data analytics is encouraged as they have proven its potential to evaluate the effect of support services. The impact of digital technologies on student support in distance and e-learning allows taking into accounts both internal and external factors and not only integrating student support with teaching and learning at different phases but also go gather data on their effectiveness automatically (Zuhairi et al., 2019, p. 15). In other words, this research emphasised the need to not only understand the value of offered support for students but also to develop instruments for measuring the result of each intervention for educational institutions in order to effectively allocate scarce economic resources.

Finally, the analysis showed two emerging trends in online students support. The first one is the increase in the use of technology and social network sites to design support interventions (Dollinger et al., 2020; Hsiao \& Huang, 2019; Marineo \& Shi, 2019). Specifically, online tools and resources are used to increase communication and decrease transactional distance (Moore \& Kearsley, 2012). Another interesting development is a shift to a more holistic approach to student support (Kelly et al., 2020; Zuhairi et al., 2019; Britto \& Rush, 2013; Johns \& Oestreich, 2019). Support strategies and services designed under a holistic approach and embrace all the aspects of the university experience, such as administrative, educational, pastoral, and personal, hold great potential for ensuring student success (Kear et al., 2016). As Brindley (2014) point out, a holistic approach to student support that is based on previous analyses of students' needs and demands, considering different learner groups and the specific characteristics of lifelong learners, will ensure that support is embedded at an institutional level. To embrace a holistic approach means to integrate different types of resources, coordinating staff to give support in academic, technical, administrative, and other relevant areas.

\section{Limitations}

Although this paper gathered valuable information on the effective support strategies and interventions, it has several limitations. First, this study did not intend to test employed IMMS model but rather used it as a frame for the analysis. As a result, some of the phases of the proposed framework are not supported by empirical evidence and discussed within the knowledge offered in the past research. This, however, allowed me to emphasise potential directions for the further research. Secondly, the study provides an analysis of the literature using a selected theoretical model which itself may need an empirical testing.

\section{Conclusion}

The reviewed literature provides a rather comprehensive set of online student support interventions and their allocation across the different phases of the learning cycle. It is suggested that the effectiveness of the implementation of these strategies and 
interventions depend on the time of student support provision, advocating the embedment of the support provision into the learning curriculum. Finally, this review indicates two under-investigated areas of student support, namely support at transition and a measurement of the effect from support interventions.

A widening participation agenda caused an emergence of the diverse online student body. Due to both the development of online learning technologies and diversification of the online student body, the provision of support services evolved, with significant variations among educational institutions. As Thorpe (2002) stated, "learner support" is the arena within which transformations in nature and the scale of activities made feasible by online teaching are generating widespread change in pedagogies and learning communities, and across institutions as a whole in ODL [online distance learning]" (p. 117).

A wide range of support interventions designed to support students at different stages suggests a need for an embedded, holistic approach to student support. Such a systemic approach may involve the development of specific policies and programmes and the integration of specialised support units and expertise across the institution. Furthermore, as the analysis showed, the time and relevancy of the provided support should not be neglected as in many cases, "support activity simply occurred too late in the course to be effective or after students had already decided to withdraw" (Gibbs et al., 2006, p. 375).

\section{Acknowledgements}

I would like to thank Professor Don Passey and two anonymous reviewers for their suggestions for improving this manuscript.

\section{Authors' contributions}

All authors read and approved the final manuscript.

Funding

This research was supported by the FfWG of the British Federation of Women Graduates, Ref: GA-00764.

Availability of data and materials

Data for the analysis was extracted from publications identified through the Scopus and Google Scholar databases and can be accessed online.

\section{Declarations}

Competing interests

No competing interests has been identified.

Received: 11 March 2021 Accepted: 25 November 2021

Published online: 06 January 2022

\section{References}

Analysed articles are marked with *

Anderson, T. (2003). Getting the mix right again: An updated and theoretical rationale for interaction. International Review of Research in Open and Distance Learning, 4(2), 1-14.

Anderson, T. (Ed.). (2008). The theory and practice of online learning. Alberta, Canada: Athabasca University Press.

Ashwin, P. (2003). Peer support: Relations between the context, process and outcomes for the students who are supported. Instructional Science, 31(3), 159-173.

Baxter, J. (2012). Who am I and what keeps me going? Profiling the distance learning student in higher education. International Review of Research in Open and Distributed Learning, 13(4), 107-129.

Boling, E. C., Hough, M., Krinsky, H., Saleem, H., \& Stevens, M. (2012). Cutting the distance in distance education: Perspectives on what promotes positive, online learning experiences. The Internet and Higher Education, 15(2), 118-126.

*Boyle, F., Kwon, J., Ross, C., \& Simpson, O. (2010). Student-student mentoring for retention and engagement in distance education. Open Learning: THe Journal of Open, Distance and e-Learning, 25(2), 115-130.

Brindley, J. E. (2014). Learner support in online distance education: Essential and evolving. In O. Zawacki-Richter \& A. Terry (Eds.), Online distance education. Towards a research agenda (pp. 287-310). AU Press. 
*Britto, M., \& Rush, S. (2013). Developing and implementing comprehensive student support services for online students. Journal of Asynchronous Learning Networks, 17(1), 29-42.

*Brown, C. J., \& Wilson, C. B. (2016). One university making a difference in graduate education: Caring in the online learning environment. Journal of Holistic Nursing, 34(4), 402-407.

Brown, A., Lawrence, J., Basson, M., \& Redmond, P. (2020). A conceptual framework to enhance student online learning and engagement in higher education. Higher Education Research \& Development, 1-16.

Cain, D., \& Lockee, B. (2002). Student support services at a distance: Are institutions meeting the needs of distance learners? ERIC Documentation Reproduction Service NED 468729.

Chen, K. C., \& Jang, S. J. (2010). Motivation in online learning: Testing a model of self-determination theory. Computers in Human Behavior, 26(4), 741-752.

Clay, M. N., Rowland, S., \& Packard, A. (2008). Improving undergraduate online retention through gated advisement and redundant communication. Journal of College Student Retention: Research, Theory \& Practice, 10(1), 93-102.

Cocquyt, C., Diep, N. A., Zhu, C., De Greef, M., \& Vanwing, T. (2017). Examining social inclusion and social capital among adult learners in blended and online learning environments. European Journal for Research on the Education and Learning of Adults, 8(1), 77-101.

Congos, D., \& Stout, B. (2003). The benefits of SI leadership after graduation. Research and Teaching in Developmental Education, 29-41.

Dahlgren, A., Hult, H., Dahlgren, L., Segerstad, H., \& Johansson, K. (2006). From senior student to novice worker: learning trajectories in political science, psychology, and mechanical engineering. Studies in Higher Education, 31, 569-86.

*Dollinger, M., Cox, S., Eaton, R., Vanderlelie, J., \& Ridsdale, S. (2020). Investigating the usage and perceptions of third-party online learning support services for diverse students. Journal of Interactive Media in Education, 1, 1-9.

Floyd, D. L., \& Casey-Powell, D. (2004). New roles for student support services in distance learning. New Directions for Community Colleges, 128, 55-64.

*Gaytan, J. (2015). Comparing faculty and student perceptions regarding factors that affect student retention in online education. American Journal of Distance Education, 29(1), 56-66.

*Gibau, G. S. (2015). Considering student voices: Examining the experiences of underrepresented students in intervention programs. CBE-Life Sciences Education, 14(3), 1-12.

Gibbs, G., Regan, P., \& Simpson, O. (2006). Improving student retention through evidence based proactive systems at the Open University (UK). Journal of College Student Retention: Research, Theory \& Practice, 8(3), 359-376.

*Glazier, R. A. (2016). Building rapport to improve retention and success in online classes. Journal of Political Science Education, 12(4), 437-456.

Grant, R., Olivier, G., Rawlings, C., \& Ross, C. (2011). Enhancing the engagement and success of distance students through targeted support programmes. The Open Polytechnic of New Zealand Working paper, 1-19.

Hew, K. F. (2015). Towards a model of engaging online students: Lessons from MOOCs and four policy documents. International Journal of Information and Education Technology, 5(6), 425-431.

*Horvath, D., Stirling, E., Bevacqua, J., Coldrey, M., Buultjens, P., Buultjens, M., \& Larsen, A. (2019). Plan, prepare and connect: How investing in understanding and tracking the evolving needs of online students informs the development of targeted programs for transition and success. Journal of University Teaching \& Learning Practice, 16(1), 1-14.

House, J. D., \& Kuchynka, S. J. (1997). The effects of a freshmen orientation course on the achievement of health science students. Journal of College Student Development, 38(5), 540-542.

*Hsiao, E., \& Huang, X. (2019). Strategies to support personal knowledge management using a wiki site in online courses. Journal of Educators Online, 16(1), 1-12.

Hussey, T., \& Smith, P. (2010). Transitions in higher education. Innovations in Education and Teaching International, 47(2), $155-164$.

Johns, E. M., \& Oestreich, S. (2019). On the edge: How to provide course-and program-integrated library support without being embedded. Journal of Library \& Information Services in Distance Learning, 13(1-2), 1-20.

Jones, B. D. (2010). An examination of motivation model components in face-to-face and online instruction. Electronic Journal of Research in Educational Psychology, 8(3), 915-944.

Karabulut-llgu, A., Jaramillo Cherrez, N., \& Jahren, C. T. (2018). A systematic review of research on the flipped learning method in engineering education. British Journal of Educational Technology, 49(3), 398-411.

*Kear, K., Rosewell, J., Williams, K., Ossiannilsson, E., Rodrigo, C., Sánchez-Elvira Paniagua, A., Santamaría Lancho, M., Vyt, A., \& Mellar, H. (2016). Quality assessment for e-learning: A benchmarking approach (third edition) [online]. European Association of Distance Teaching Universities (EADTU). Retrieved from http://e-xcellencelabel.eadtu.eu/images/Excellence_manual_2016_third_edition.pdf.

*Kelly, A., Johnston, N., \& Matthews, S. (2020). Online self-access learning support during the COVID-19 pandemic: An Australian University case study. Studies in Self-Access Learning Journal, 11(3), 187-198.

*Kumar, S., \& Coe, C. (2017). Mentoring and student support in online doctoral programs. American Journal of Distance Education, 31(2), 128-142.

*Kumar, S., \& Johnson, M. (2017). Mentoring doctoral students online: Mentor strategies and challenges. Mentoring \& Tutoring: Partnership in Learning, 25(2), 202-222.

*Kuo, Y. C., \& Belland, B. R. (2016). An exploratory study of adult learners' perceptions of online learning: Minority students in continuing education. Educational Technology Research and Development, 64(4), 661-680.

LaPadula, M. (2003). A comprehensive look at online student support services for distance learners. The American Journal of Distance Education, 17(2), 119-128.

Lee, Y., \& Choi, J. (2011). A review of online course dropout research: Implications for practice and future research. Educational Technology Research and Development, 59(5), 593-618.

Maunder, R. E., Cunliffe, M., Galvin, J., Mjali, S., \& Rogers, J. (2013). Listening to student voices: Student researchers exploring undergraduate experiences of university transition. Higher Education, 66(2), 139-152.

*Marineo, F., \& Shi, Q. (2019). Supporting student success in the first-year experience: Library instruction in the learning management system. Journal of Library \& Information Services in Distance Learning, 13(1-2), 40-55. 
Martin, F., \& Bolliger, D. U. (2018). Engagement matters: Student perceptions on the importance of engagement strategies in the online learning environment. Online Learning, 22(1), 205-222.

*McDougall, J. (2019).'I never felt like I was alone': A holistic approach to supporting students in an online, pre-university programme. Open Learning: THe Journal of Open, Distance and e-Learning, 34(3), 241-256.

McKavanagh, M., \& Purnell, K. (2007). Student learning journey: Supporting student success through the student readiness questionnaire. Studies in Learning, Evaluation, Innovation and Development, 4(2), 27-38.

McLean, M. (2004). Does the curriculum matter in peer mentoring? From mentee to mentor in problem-based learning: A unique case study. Mentoring \& Tutoring: Partnership in Learning, 12(2), 173-186.

*McLoughlin, C. E., \& Alam, S. L. (2014). A case study of instructor scaffolding using Web 2.0 tools to teach social informatics. Journal of Information Systems Education, 25(2), 125-136.

Merrill, B. (2020). Biographical Inquiry: A Collaborative and Egalitarian Approach to Adult Education Research. In B. Grummell \& F. Finnegan (Eds.), Doing Critical and Creative Research in Adult Education (pp. 15-24). Leiden, Netherlands: Brill.

Miller, T., \& Prince, J. (1976). The future of student affairs. A guide to student development for tomorrow's higher education. Jossey-Bass.

Moore, M. G., \& Kearsley, G. (2012). Distance education: A systematic view of online learning (3rd ed.). Wadsworth Cengage Learning.

Muldoon, R. (2008). Recognising and rewarding the contribution and personal development of peer supporters at university. Journal of Further and Higher Education, 32(3), 207-219.

Muljana, P. S., \& Luo, T. (2019). Factors contributing to student retention in online learning and recommended strategies for improvement: A systematic literature review. Journal of Information Technology Education Research, 18, 19-57.

*Netanda, R. S., Mamabolo, J., \& Themane, M. (2019). Do or die: Student support interventions for the survival of distance education institutions in a competitive higher education system. Studies in Higher Education, 44(2), 397-414.

*Nicholas, D. B., Fellner, K. D., Frank, M., Small, M., Hetherington, R., Slater, R., \& Daneman, D. (2012). Evaluation of an online education and support intervention for adolescents with diabetes. Social Work in Health Care, 51(9), 815-827.

*Nichols, M. (2010). Student perceptions of support services and the influence of targeted interventions on retention in distance education. Distance Education, 31(1), 93-113.

Nistor, N., \& Neubauer, K. (2010). From participation to dropout: Quantitative participation patterns in online university courses. Computers \& Education, 55(2), 663-672.

Öztok, M. (2019). The hidden curriculum of online learning: understanding social justice through critical pedagogy. Routledge.

Paechter, M., Maier, B., \& Macher, D. (2010). Students' expectations of, and experiences in e-learning: Their relation to learning achievements and course satisfaction. Computer Education, 54(1), 222-229.

Pinchbeck, J., \& Heaney, C. (2017). Case report: The impact of a resubmission intervention on level 1 distance learning students. Open Learning: THe Journal of Open, Distance and e-Learning, 32(3), 236-242.

*Purnell, K., McCarthy, R., \& McLeod, M. (2010). Student success at university: Using early profiling and interventions to support learning. Studies in Learning, Evaluation, Innovation and Development, 7(3), 77-86.

Reay, D. (2003). A Risky Business? Mature Working-class Women Students and Access to Higher Education. Gender and Education, 15(3), 301-17.

Rendon, L. I. (1994). Validating culturally diverse students: Toward a new model of learning and student development. Innovative Higher Education, 19(1), 33-51.

Rice, M., Lowentha, P., \& Woodley, X. (2020). Distance education across critical theoretical landscapes: Touchstones for quality research and teaching. Distance Education, 41(3), 319-325.

Richardson, J. C., Maeda, Y., Lv, J., \& Caskurlu, S. (2017). Social presence in relation to students'satisfaction and learning in the online environment: A meta-analysis. Computers in Human Behavior, 71, 402-417.

Rienties, B., \&Toetenel, L. (2016). The impact of learning design on student behaviour, satisfaction and performance: A cross-institutional comparison across 151 modules. Computers in Human Behavior, 60, 333-341.

*Robb, C. A., \& Sutton, J. (2014). The importance of social presence and motivation in distance learning. The Journal of Technology, Management, and Applied Engineering, 31(2), 2-10.

Rotar, O. (2020). A missing element of online HE students' attrition, retention, and success: an analysis through a systematic literature review (Working Paper No. 3). Retrieved from https://www.lancaster.ac.uk/educational-research/resea rch/centre-for-higher-education-research-and-evaluation/working-papers/

Rovai, A. (2003). In search of higher persistence rates in distance education online programs. The Internet and Higher Education, 6(1), 1-16.

Rumble, G. (2000). Student support in distance education in the 21st century: Learning from service management. Distance Education, 21(2), 216-235.

Russo-Gleicher, R. J. (2013). Qualitative insights into faculty use of student support services with online students at risk: Implications for student retention. Journal of Educators Online, 10(1), 1-32.

Ryan, Y. (2004). Pushing the boundaries with online learner support. In J. Brindley, C. Walti, \& O. Zawacki-Richter (Eds.), Learner support in open, distance and online learning environments (pp. 125-134). Bibliotheks und Informations system der Universität Oldenburg.

Sewart, D. (1993). Student support systems in distance education. Open Learning: THe Journal of Open, Distance and e-Learning, 8(3), 3-12.

Simpson, O. (2003). Student retention in online open and distance learning. Kogan Page.

Simpson, O. (2004). The impact on retention of interventions to support distance learning students. Open Learning: THe Journal of Open, Distance and e-Learning, 19(1), 79-95.

Simpson, O. (2008). Motivating learners in open and distance learning: Do we need a new theory of learner support? Open Learning: THe Journal of Open, Distance and e-Learning, 23(3), 159-170.

*Sisselman-Borgia, A. G., \& Torino, G. C. (2017). Innovations in experiential learning for adult learners. Journal of Applied Learning in Higher Education, 7, 3-13.

*Smailes, J., \& Gannon-Leary, P. (2011). Peer mentoring —Is a virtual form of support a viable alternative? Research in Learning Technology, 19(2), 129-142. 
Sorensen, C., \& Donovan, J. (2017). An examination of factors that impact the retention of online students at a for-profit university. Online Learning, 21(3), 206-221.

Stone, C. (2017). Opportunity through online learning: Improving student access, participation and success in higher education (NCSEHE 2016 Equity Fellowship Final Report). Perth: Curtin University, National Centre for Higher Education. Retrieved from https://www.ncsehe.edu.au/publications/opportunity-online-learning-improving-stude nt-access- participation-success-higher-education/

Stone, C. (2019). Online learning in Australian higher education: Opportunities, challenges and transformations. Student Success, 10(2), 1-11.

Stone, C., \& O'Shea, S. (2019). Older, online and first: Recommendations for retention and success. Australasian Journal of Educational Technology, 35(1), 57-69.

Tait, A. (2004). On institutional models and concepts of student support services: The case of the Open University, UK, 3rd EDEN Research Workshop. Retrieved from http://www.c3l.uni-oldenburg.de/cde/support/fa04/Nol.\%209\%20cha pters/KeynoteTait.pdf

Tett, L. (2000). 'I'm Working Class and Proud of It' - Gendered Experiences of Non-traditional Participants in Higher Education. Gender and Education, 12(2), 183-94.

Thorpe, M. (2002). Rethinking learner support: The challenge of collaborative online learning. Open Learning: THe Journal of Open, Distance and e-Learning, 17(2), 105-119.

Tinto, V. (1975). Dropout from higher education: A theoretical synthesis of recent research. Review of Educational Research, 45(1), 89-125.

Tippens, D. (2012). Technology has its place: Behind a caring teacher. Chronicle of Higher Education. Retrieved from http://chronicle.com/article/technology-has-itsplace-133328/

*Uribe, S. N., \& Vaughan, M. (2017). Facilitating student learning in distance education: A case study on the development and implementation of a multifaceted feedback system. Distance Education, 38(3), 288-301.

*Walsh, C., Mital, A., Ratcliff, M., Yap, A., \& Jamaleddine, Z. (2020). A public-private partnership to transform online education through high levels of academic student support. Australasian Journal of Educational Technology, 36(5), 30-45.

*Walters-Archie, A. (2018). Academic support for online students in the English-speaking Caribbean at the University of the West Indies Open Campus. Journal of Further and Higher Education, 42(6), 868-878.

Ward, T., \& Commander, N. E. (2011). The power of student voices: An investigation of the enduring qualities of freshmen learning communities. Journal of College Student Retention: Research, Theory \& Practice, 13(1), 63-85.

Whitelock, D. (2010). Activating Assessment for Learning: are we on the way with Web 2.0? In M. J. W. Lee \& C. McLoughlin (Eds.), Web 2.0- Based-E-Learning: Applying Social Informatics for Tertiary Teaching (pp. 319-342). Hershey, PA: IGI Global.

*Whitelock, D., Thorpe, M., \& Galley, R. (2015). Student workload: A case study of its significance, evaluation and management at the Open University. Distance Education, 36(2), 161-176.

Williford, A. M., Chapman, L. C., \& Kahrig, T. (2001). The university experience course: A longitudinal study of student performance, retention, and graduation. Journal of College Student Retention: Research, Theory \& Practice, 2(4), 327-340.

Wilson, M. (2008). An investigation into the perceptions of first-time online undergraduate learners on orientation events. Journal of Online Teaching and Learning, 4(1), 73-83.

Woodley, A., \& Simpson, O. (2014). The elephant in the room. In Online Distance Education: Towards a Research Agenda (pp. 459-485).

Zawacki-Richter, O., \& Anderson, T. (2014). Online distance education: Towards a research agenda. AU Press.

Zuhairi, A., Karthikeyan, N., \& Priyadarshana, S. T. (2019). Supporting students to succeed in open and distance learning in the Open University of Sri Lanka and Universitas Terbuka Indonesia. Asian Association of Open Universities Journal, 13-34

\section{Publisher's Note}

Springer Nature remains neutral with regard to jurisdictional claims in published maps and institutional affiliations.

\section{Submit your manuscript to a SpringerOpen ${ }^{\circ}$ journal and benefit from:}

- Convenient online submission

- Rigorous peer review

- Open access: articles freely available online

High visibility within the field

- Retaining the copyright to your article

Submit your next manuscript at $\gg$ springeropen.com 